\title{
Extinction responding following amphetamine self-administration: Determination of reinforcement magnitude
}

\author{
ROBERT A. YOKEL and ROY PICKENS \\ University of Minnesota, Minneapolis, Minnesota 55455
}

\begin{abstract}
Several measures of extinction responding were observed following responding for one of several doses of either dextro or levo amphetamine or dextro or levo methylamphetamine to compare reinforcement magnitudes. After daily 6 -h sessions of intravenous self-administration of drug, the drug was replaced by saline and extinction behavior observed. The number of responses to extinction did not differ significantly between drugs and doses used, but extinction times were greater for the larger doses and the dextro isomers. Response rate during extinction appeared to be a function of response rate during drug access, suggesting that the rate of responding was conditioned during drug self-administration. Response rate during extinction and time to complete extinction do not appear to be reliable indicators of reinforcement magnitude due to this conditioning effect.
\end{abstract}

Rats and monkeys will leverpress for intravenous injections of many of the same drugs that humans abuse (Schuster \& Thompson, 1969). The behavior maintained by these drug injections is similar in many ways to behavior maintained by other reinforcers. Response rate is a function of the amount of drug or food presented. responding is not maintained when drug is no longer available, and a rat will rapidly learn to perform a new response to obtain drug (Pickens \& Thompson, 1968). Furthermore, the pattern of responding for drug under simple schedules of reinforcement is similar to that seen for other reinforcers (Pickens \& Thompson, 1972).

It has been shown that rats will self-administer the dextro and levo isomers of amphetamine and methylamphetamine over a wide range of injection doses (Yokel \& Pickens, 1973). It is of interest to determine if all doses of these four compounds, and the compounds themselves, are equally reinforcing. Response rate has often been used as an indicator of reinforcement magnitude; however, response rate for stimulant injections has repeatedly been shown to be an inverse function of the injection dose, with higher response rates seen for lower injection doses. This results in a relatively constant amount of drug consumed $(\mathrm{mg} / \mathrm{kg} / \mathrm{h})$ across a wide range of injection doses (Deneau, Yanagita, \& Seevers, 1969; Pickens \& Thompson, 1968; Yokel \& Pickens, 1973). Within this range of doses. each injection produces drug satiation, and the rate of responding reflects the length of the subsequent satiation period. Therefore, rate cannot be used to determine the reinforcement

The authors wish to thank Abbott Laboratories for their generous donation of levomethylamphetamine and Drs. Jane Stewart and Roy Wise for their many helpful suggestions in preparing this manuscript. magnitude of various doses of the various amphetamine compounds.

One method often used to compare reinforcement magnitude for various reinforcers, or various amounts or concentrations of the same reinforcer, is to withhold reinforcement from an animal and observe the behavior during extinction (Armus, 1959; Fitts, 1940; Guttman. 1953; Hutt, 1954; McCloskey \& Tombaugh, 1971; Roberts, 1969). It has been shown that cessation of responding follows termination of drug availability after self-administration of the drug, but this extinction of responding has not been systematically studied following drug self-administration. A study of extinction behavior following self-administration of various doses of the amphetamines, and different forms of amphetamines, dextro and levo amphetamine and dextro and levo methylamphetamine, should provide information relative to the reinforcement magnitude of these drug injections and further test the suggestion that drugs as reinforcers have similar properties as other reinforcers, such as food, water, and sugar solutions (Pickens \& Thompson, 1968). The isomers of the amphetamines are good drugs to use for this purpose as they are similar compounds, differing mainly in potency. This experiment compares several extinction parameters following sessions of responding for varying doses of each of the four amphetamine compounds.

\section{METHOD}

Sixteen male Holtzman albino rats, 101 to 223 days old and weighing $352-606 \mathrm{~g}$, were intravenously catheterized under methoxyflurane anesthesia, as described previously (Pickens \& Thompson, 1968). Each subject was individually housed for the duration of the experiment in a $10 \times 10 \times 9$ in. high ventilated, sound-attenuated operant conditioning chamber containing ad-lib 
food (Purina Rat Chow) and water. Two response levers and a small stimulus light were mounted on one cage wall. One lever was programmed to deliver after each response a $0.50-\mathrm{ml} 30-\mathrm{sec}$ drug injection, during which the stimulus light was illuminated; the other lever served as a control lever (for unconditioned activity effects of the drugs) and had no programmed consequence. The subjects were divided into three groups. Initially, a low-dose amphetamine group containing six rats was run. Rats responded for drug injections of $0.25,0.5,0.75$, or $1.0 \mathrm{mg} / \mathrm{kg}$ of either dextro or levo amphetamine sulfate on any one day for $6 \mathrm{~h}$. Each rat responded daily for one of the eight possible dose-isomer combinations. Drug dose and isomer were randomly presented. A second group of four rats was run in a similar procedure, however the drugs were dextro and levo methylamphetamine and the injection doses were $1.0,1.5,2.0$, and $2.5 \mathrm{mg} / \mathrm{kg}$. The larger doses were used because levo methylamphetamine does not maintain responding in the rat below $1.0 \mathrm{mg} / \mathrm{kg} /$ injection (Yokel \& Pickens, 1973). To compare the results obtained with this methylamphetamine group to amphetamine, a third group of six rats, the high-dose amphetamine group, was run with injection doses of dextro and levo amphetamine of $1.0,1.5,2.0$, and $2.5 \mathrm{mg} / \mathrm{kg}$. Daily sessions were continued for each animal until the catheter no longer functioned. For all three groups, data were obtained from each rat for self-administration sessions with at least two of the four injection doses with the dextro, and at least two of the four injection doses of the levo isomer of either amphetamine or methylamphetamine. Therefore, data were not obtained from all rats at all dose-isomer combinations, and multiple observations were obtained from some animals.

Each day, subjects were allowed $6 \mathrm{~h}$ of self-administration. After $6 \mathrm{~h}$, the drug solution was replaced by saline. Extinction responding was recorded until $2 \mathrm{~h}$ had elapsed with no more than one response for saline having been made. Recorded for each session were: the time taken to reach this extinction criterion, extinction time; the time to emission of half of the total number of extinction responses, extinction half-time; the number of responses in the first hour of extinction; and the total number of extinction responses to criterion. Extinction responding was calculated from the second response after drug removal, as the first two responses contained some drug solution remaining in the catheter tubing following substitution of saline. Stimulus light presentations were continued in extinction as during conditioning.

Comparisons of each of the four extinction parameters were made within each of the three independent groups, rather than across groups. The within-group comparison and random presentation of isomer and dose limited carry-over effects from one session to another.

Drugs used were dextro and levo amphetamine sulfate (K \& $\mathrm{K}$ Laboratories, Plainview, N.Y.), dextro methylamphetamine hydrochluride (Sigma Chemical Company, St. Louis, Mo.), and levomethylamphetamine hydrochloride (Abbott Laboratories, North Chicago, Ill.). All drugs were dissolved in normal saline solution. Injection doses are expressed as the salt.

\section{RESULTS}

During the $6 \mathrm{~h}$ of drug self-administration, the response rate was lower (and the mean interresponse time longer) for the larger injection doses than for the smaller doses and was lower (and the mean interinjection interval longer) for the dextro than for the levo isomers at the same dose (Figure 1). These data agree with previous reports that response rate is an inverse function of injection dose.

The pattern of responding following termination of amphetamine availability was seen to be similar to that found following termination of availability of

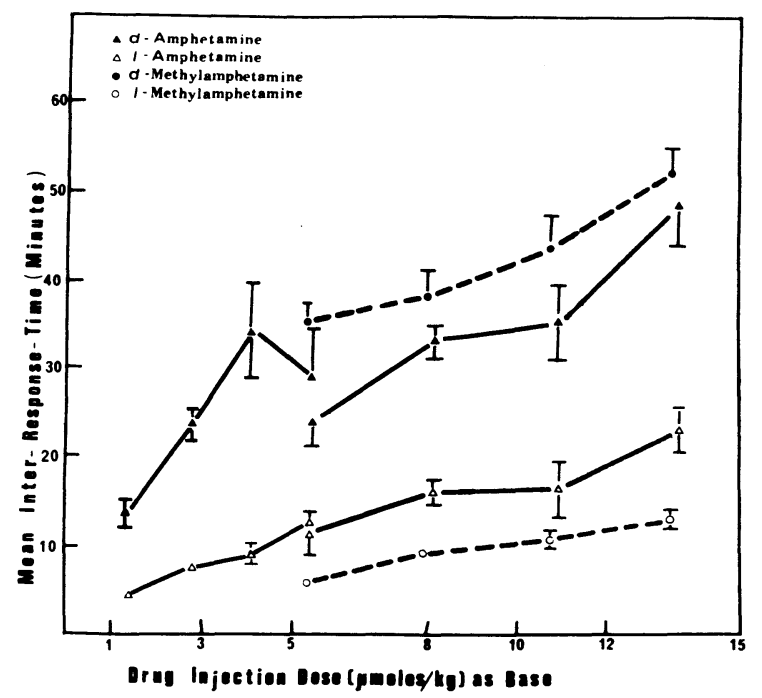

Figure 1. Mean inter response time during $6 \mathrm{~h}$ of drug self-administration as a function of injection dose of amphetamine and methylamphetamine isomers. All values are means $\pm \mathrm{SE}$ (verticle lines) in $\mu$ moles $/ \mathrm{kg}$ of base. Solid lines and triangles are for the two amphetamine groups. Dashed lines and circles are for the methylamphetamine group.

classical reinforcers such as food, water, etc., in that responding initially increased, then ceased altogether. An analysis of the responding during the extinction period was made by comparing, for each response measure, the results obtained after an initial exposure to a given dose of one isomer with the results obtained on a subsequent exposure to the same dose of the other isomer in the same animal. Sign tests were used to compare the dextro and levo isomers within each animal, and the probabilities of these test results were combined for all animals within each of the three drug groups in a chi-square analysis (Winer, 1962, pp. 43-45). The statistical comparisons are shown in Table 1 for each of the four parameters.

Figure 2 shows the mean $( \pm S E)$ number of responses to extinction for each dose and isomer tested. As can be seen, although there are a greater number of responses to extinction following dextro

Table 1

Extinction Half-Time as a Percentage of the Time to Extinction Criterion (Extinction Time), and the Pearson Product Correlation Coefficient Between the Two Times

\begin{tabular}{lccc}
\hline & \multicolumn{2}{c}{ Extinction Half-Time } \\
\cline { 2 - 3 } & & $\begin{array}{c}\text { Extinction } \\
\text { Time } \\
\text { (Percentage) }\end{array}$ & $\begin{array}{c}\text { Correlation } \\
\text { Coefficient }\end{array}$ \\
\hline Low-Dose Amphetamine & $\mathrm{d}$ & 55.8 & $\mathrm{r}=.95$ \\
High-Dose Amphetamine & $\mathrm{d}$ & 41.4 & $\mathrm{r}=.97$ \\
Methylamphetamine & $\mathrm{d}$ & 55.4 & $\mathrm{r}=.84$ \\
& $\mathrm{~d}$ & 36.2 & $\mathrm{r}=.84$ \\
& $\mathrm{~d}$ & 61.6 & $\mathrm{r}=.99$ \\
& & 41.4 & $\mathrm{r}=.97$ \\
\hline
\end{tabular}




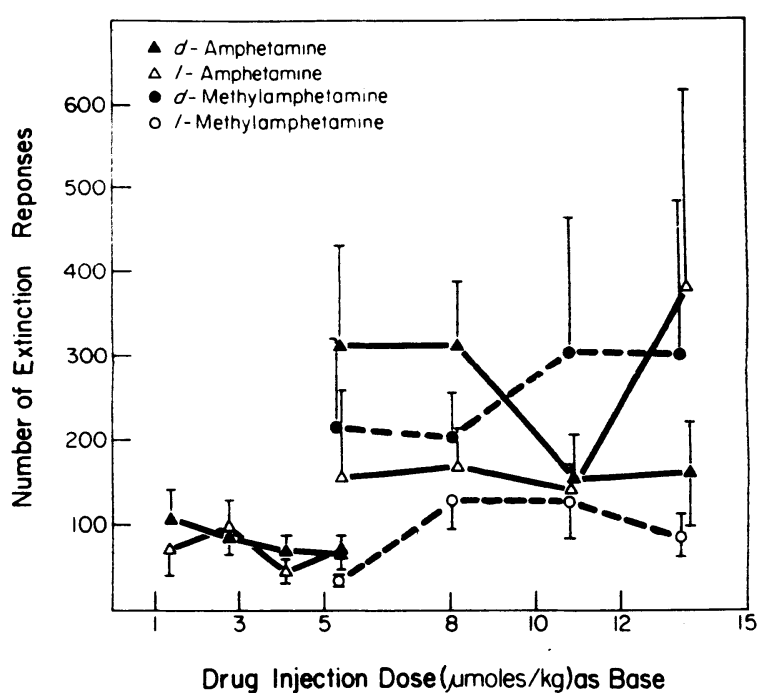

Figure 2. Number of responses during extinction as a function of injection dose of amphetamine and methylamphetamine isomers. All values are means $\pm S E$ (verticle lines) in $\mu$ moles $/ \mathrm{kg}$ of base. Solid lines and triangles are for the two amphetamine groups. Dashed lines and circles are for the methylamphetamine group.

than following the levo isomer for both amphetamine and methylamphetamine at several injection doses, this was not a consistent effect at all doses, nor was there a significant difference between the largest and smallest injection dose within any of the three groups of animals ( $t$ tests of means, $p>.1$ in all cases).

Within each of the three groups of rats, significant differences were seen between the dextro and levo isomers for both the extinction time and extinction half-time. For a given injection dose, a longer time was required to reach extinction or to emit $50 \%$ of the total extinction responses for the dextro than for the levo isomer (see Figure 3). The extinction half-time was about one-half that of the total extinction time (see Table 1), indicating that the response rate during extinction was fairly uniform, with half of the extinction responses emitted within half of the total time to extinction. Extinction half-time also increases with increases in dose.

Finally, the number of responses during the first hour of extinction were fewer after the dextro than after the levo isomers, and were fewer after the higher

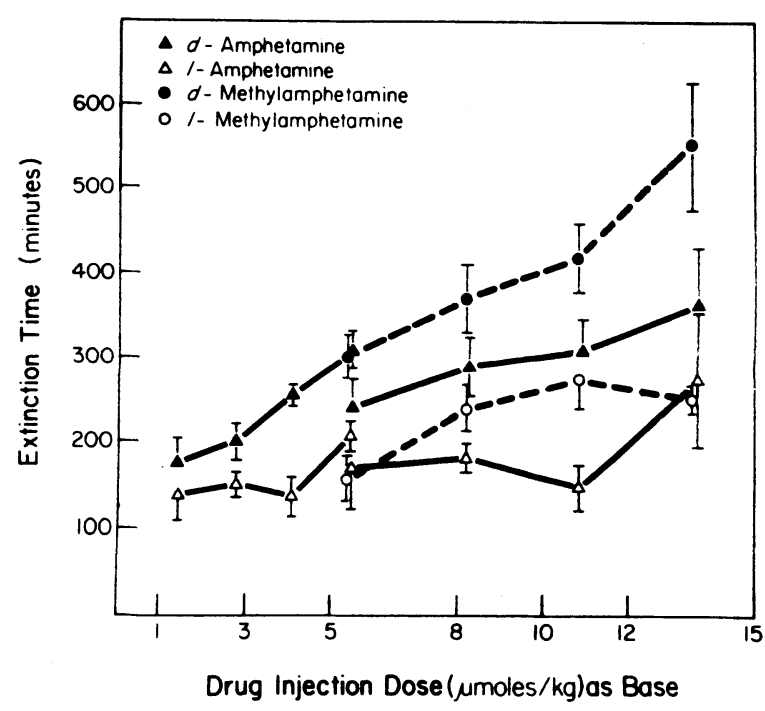

Figure 3. Time to extinction, in minutes, as a function of injection dose of amphetamine and methylamphetamine isomers. All values are means $\pm S E$ (verticle lines) in $\mu$ moles $/ \mathrm{kg}$ of base. Solid lines and triangles are for the amphetamine groups. Dashed lines and circles are for the methylamphetamine group.

than after the lower doses (Table 2). This should be the case if the number of extinction responses remains relatively constant for all isomers and doses while the time taken to reach the extinction criterion increases with higher doses and is greater for the dextro than for the levo isomers.

\section{DISCUSSION}

The pattern of responding after termination of amphetamine reinforcement was characteristic of the response pattern seen during extinction following responding for classical reinforcers which had also been presented on a continuous reinforcement schedule, i.e., an increase in response rate followed by response termination. This finding further supports the general view that intravenous drug reinforcement has the same characteristics as classical reinforcers (Pickens \& Thompson, 1968).

Although no significant difference was seen in the number of responses to extinction following dextro and levo isomer self-administration, the time to

Table 2

Comparisons Between Dextro and Levo Isomers at the Same Injection Dose for Each of the Four Extinction Parameters Measured

Low-Dose Amphetamine High-Dose Amphetamine

Total Extinction Responses

Time to Extinction Criterion

Extinction Half-Time

Extinction Responses in the First Hour

$\begin{array}{ll}d>1 & d>1 \\ p>.05 & p>.05 \\ d>1 & d>1 \\ p<.02 & p<.001 \\ d>1 & d>1 \\ p<.01 & p<.01 \\ d<1 & d<1 \\ p<.01 & p<.02\end{array}$

MethylAmphetamine

d $>1$

$\mathrm{p}>.05$

d $>1$

$\mathrm{p}<.001$

$\mathrm{d}>1$

$\mathrm{p}<.001$

$\mathrm{d}<1$

$\mathrm{p}<.001$

Note-See Results section for statistical tests used. 
complete extinction and the extinction half-time were found to be greater with the dextro than with levo isomers, and found to increase as the injection dose was increased. After self-administration of the higher doses and/or the dextro isomers, animals distribute their extinction responses over a longer period of time without emitting a greater total number of extinction responses.

It has been previously shown that rats self-administering intravenous amphetamine respond for the next drug injection when their blood amphetamine level drops to some absolute level, regardless of size of the injection dose (Yokel \& Pickens, 1974). Therefore, in the present study, it can be argued that the amount of active drug in an animal at the beginning of extinction should have been constant for any given isomer. Thus, the differences in time to extinction after different doses of the same isomer would appear not to be explainable in terms of differences in blood level when extinction began, i.e., unconditioned drug effects should not have influenced extinction responding.

The increased time to extinction seen with larger doses of the same isomer, and for the dextro as compared to the levo isomer, may reflect a conditioning of longer interresponse times with the dextro isomers and the higher injection doses during the 6-h session of responding for drug injections. Comparison of Figure 1 to Figure 3 illustrates the similarity in the temporal response patterns during performance and extinction. Comparison of Figure 1 to Figure 2 suggests that there is no influence on the number of extinction responses by the drug injection dose. It appears that a different mechanism may control the response pattern in extinction than controls the number of responses seen in extinction.

Milstead (1970) varied the intertrial interval during acquisition of a running response for food reinforcement in a discrete trial procedure, and found that resistance to extinction, as measured by running time, was a function of the intertrial interval. Similarly, squirrel monkeys which had had previous experience intravenously self-administering dextro amphetamine responded for intravenous saline injections after receiving a noncontingent amphetamine injection. The rate of responding for saline was observed to be greater after $1 \mathrm{mg} / \mathrm{kg}$ than after 0.3 or $0.15 \mathrm{mg} / \mathrm{kg}$ of amphetamine. These results further demonstrate a conditioning of response rate by the reinforcer, amphetamine (Stretch \& Gerber, 1973). Previous reports of rats responding for food of varying palatability and amount, or for sucrose in varying concentrations and for varying levels of light in a dark chamber, have demonstrated that patterns of responding during acquisition are continued during extinction (Guttman, 1953; Hutt, 1954; Stewart, 1960).

The results of the present study thus confirm and call attention to those of other studies of extinction after responding for reinforcement, i.e., extinction measures such as response rate and time to complete extinction do not provide a good measure of reinforcement magnitude for varying amounts and concentrations of reinforcers, because the pattern of behavior prevalent during reinforcement presentation is carried into extinction responding, resulting in a conditioned pattern of responding. This finding would seem to have important implications for programs attempting to extinguish drug seeking and taking behavior by humans, in that being aware of the pattern of behavior during performance should facilitate predicting the behavior during extinction.

\section{REFERENCES}

ARmus, H. L. Effect of magnitude of reinforcement on acquisition and extinction of a running response. Journal of Experimental Psychology, 1959, 58, 61-63.

Deneau, G., Yanagita, T., \& Seevers, M. H. Selfadministration of psychoactive substances by the monkey. Psychopharmacologia, 1969, 16, 30-48.

FirTs, P. M. The effect of a large and a small reward as indicated by the resistance-to-extinction curves for the rat. Psychological Bulletin, 1940, 37, 429-430.

Guttman, N. Operant conditioning, extinction and periodic reinforcement in relation to concentration of sucrose used as reinforcing agent. Journal of Experimental Psychology, 1953, 46, 213-224.

Hurt, P. J. Rate of bar pressing as a function of quality and quantity of food reward. Journal of Comparative and Physiological Psychology, 1954, 47, 235-239.

McCloskey, J. L., \& Tombaugh, T. N. The effects of volume of sucrose reward on resistance to extinction. Psychological Record, 1971, 21, 53-57.

MilsteAD, J. R. Interactive effects of reward magnitude and inter-trial intervals on resistance to extinction. Dissertation Abstracts, 1970, 31, 1567.

Pickens, R., \& Thompson, T. Cocaine-reinforced behavior in rats: Effects of reinforcement magnitude and fixed-ratio size. Journal of Pharmacology and Experimental Therapeutics, $1968,161,122-129$.

Pickens, R., \& Thompson, T. Simple schedules of drug selfadministration in animals. In J. M. Singh, L. H. Miller, \& H. Lal (Eds.), Drug addiction: Experimental pharmacology (Vol. 1). Mount Kisco, N.Y: Future, 1972. Pp. 107-120.

ROBERTs, W. A. Resistance to extinction following partial and consistent reinforcement with varying magnitude of reward. Journal of Comparative and Physiological Psychology, 1969, 67, 395-400.

Schuster, C. R., \& Thompson, T. Self-administration of and behavioral dependence on drugs. Annual Review of Pharmacology, 1969, 9, 483-502.

STEwART, J. Reinforcing effects of light as a function of intensity and reinforcement schedule. Journal of Comparative and Physiological Psychology, 1960, 53, 187-193.

Stretch, R., \& Gerber, G. J. Drug induced reinstatement of amphetamine self-administration behaviour in monkeys. Canadian Journal of Psychology, 1973, 27, 168-177.

WINER, B. J. Statistical principles in experimental design. New York: McGraw-Hill, 1962.

Yokel, R. A., \& Pickens, R. Self-administration of optical isomers of amphetamine and methylamphetamine by rats: Acute and chronic effects. Journal of Pharmacology and Experimental Therapeutics, 1973, 187, 27-33.

Yokel, R. A., \& Pickens, R. Drug level of d-and 1-amphetamine during intravenous self-administration. Psychopharmacologia, $1974,34,255-264$.

(Received for publication November 18, 1974; revision received July 22,1975 .) 